\title{
Paradojas de la inmigración mexicana a Estados Unidos en áreas de la salud
}

\author{
Paradoxes of Mexican immigrants \\ to the United States in the health sector
}

Selene Gaspar Olvera*

ISSN IMPRESO 1870-7599 | ISSN RED CÓMPUTO 2448-7783 | 49-82 RECIBIDO 10/01/19 | ACEPTADO 23/03/19

\begin{abstract}
Resumen. En el curso de las últimas tres décadas la migración altamente calificada no sólo se ha incrementado, sino que experimenta un viraje hacia campos del conocimiento vinculados con la innovación, en particular en las áreas de ciencia, tecnología, ingeniería y matemáticas (CTIM). No obstante, resulta importante advertir que a la par de este trascendental cambio, México exhibe un déficit de médicos y enfermeras acompañado de una emigración de recursos humanos formados en áreas de la salud hacia Estados Unidos y subvalorados en el mercado laboral de ese país, con un tercio de ellos ubicado en actividades no calificadas y un cuarto en actividades distintas a la atención de la salud. A pesar de ser subvalorados su media salarial supera hasta en seis veces el salario que obtendrían en México. Mediante un análisis multivariado binomial se examinan los factores individuales, de capital humano y ocupación, que favorecen este comportamiento.
\end{abstract}

Palabras clave: profesionales de la salud, migración, déficit, envejecimiento, México-Estados Unidos.

Abstract. Over the past three decades, highly qualified migration has not only increased, but also experienced a shift towards fields of knowledge linked to innovation, particularly in the areas of science, technology, engineering and mathematics (STEM). However, it should be noted that along with this transcendental turn, Mexico has a shortage of doctors and nurses together with an emigration of human resources trained in health professions and undervalued in the US labor market, with a third of them employed in unskilled activities and a quarter in activities other than health care. Despite being undervalued, their average salary is up to six times higher than what they would earn in Mexico. Through a multivariate binomial analysis, the individual, human capital and occupation factors that favor this behavior are analyzed.

Keywords: health professionals, migration, deficit, aging, Mexico-United States.

\footnotetext{
* Mexicana. Maestra en Demografía Social y Actuaría por la Universidad Nacional Autónoma de México, investigadora adscrita a la Unidad Académica en Estudios del Desarrollo de la Universidad Autónoma de Zacatecas en el proyecto Sistema de Información sobre Migración y Desarrollo (SIMDE-UAZ). Correo-e: selene. gasparolvera@gmail.com
} 


\section{Introducción}

Desde mediados del siglo XX la migración ha sido estudiada por distintas disciplinas de las ciencias sociales (Chacón, 2002). Su importancia radica en que la migración, lejos de fungir como un subsidio Norte-Sur y una palanca de desarrollo para los países de origen, como lo pregona el Banco Mundial, obstaculiza el desarrollo y amplía las desigualdades individuales, familiares, locales y regionales. Las causas que motivan a las personas a moverse entre fronteras nacionales son diversas, así como los tipos de migraciones o grupos de migrantes. Uno de esos grupos son los prestadores de servicios de salud, cuyo estudio se ha convertido en un tema relevante por su magnitud y por las implicaciones que tiene sobre la atención de la salud de la población en los países emisores con déficit de personal en áreas de la salud y en proceso de envejecimiento. En un contexto de apertura para algunos tipos de migrantes y de cierre de oportunidades legales de ingreso para otros, el neoliberalismo favorece la migración calificada hacia los países centrales o desarrollados (Aragonés y Salgado, 2014). La migración internacional de trabajadores de la salud, médicos y enfermeras, hacia países de la Organización para la Cooperación y el Desarrollo Económicos (OCDE), aumentó en 60 por ciento durante la última década, al pasar de 1.1 millones a 1.8 millones (WHO). ${ }^{1}$

La globalización neoliberal ha propiciado la movilidad, en especial a los países desarrollados, de personas con estudios superiores en casi cualquier ámbito disciplinario. De aquí que la migración de los profesionales en los distintos campos del conocimiento revista creciente importancia en relación con las dinámicas de desarrollo social y económico desigual entre las naciones receptoras y expulsoras. En este contexto, existen profesionales, como los dedicados a la salud, que tienen un mayor impacto directo en la población y en los sistemas económicos en los que ejercen su profesión.

Así, el estudio de la fuerza laboral migrante en el campo de la salud puede tener repercusiones en el funcionamiento del sistema de salud, con consecuencias sobre los individuos y sus familias en los distintos niveles geográficos que componen un territorio nacional y supranacional. El funcionamiento de los sistemas de salud depende de la disponibilidad de recursos humanos, «competentes y 
comprometidos, pero a la vez en número suficiente, adecuadamente distribuidos y con trabajo y salario dignos» (OPS, 2013:15). La capacidad de respuesta de los sistemas de salud depende del tamaño, composición, distribución y productividad de su fuerza laboral, entre otros factores. La Organización Mundial de la Salud (OMS, 2013) señala que la escasez de recursos humanos de la salud podría llegar hasta 12.9 millones en 2035 y advierte que, de no ser abordado el problema, podría tener serias repercusiones para la salud de millones de personas en todas las regiones del mundo (OCDE, 2016).

México se ubica entre los países con déficit en los niveles nacional y estatal, que a su vez se encuentran en un estadio avanzado de su transición demográfica, lo que plantea nuevos retos para atender las necesidades presentes y futuras de tales servicios (Ávila y Gaspar, 2019). Ocupa la décima posición mundial por el número de médicos y enfermeras nacidos en él que radican fuera, con Estados Unidos como principal receptor, a lo que se agrega un avanzado proceso de envejecimiento y un sensible déficit de prestadores de salud (OCDE, 2016). Fajardo, Santacruz y Lavalle (2015:XX) exponen, en este sentido, que la planificación de recursos humanos en salud no debe realizarse sin considerar el fenómeno de la migración, pues «los problemas tanto de exceso como de falta de médicos son cíclicos y suelen afectar de manera simultánea a todos los países». Ante un contexto de déficit de profesionales de la salud en México y en Estados Unidos y con ambas naciones en un proceso de envejecimiento, aunque con distinta intensidad, las asimetrías de desarrollo y la vecindad geográfica seguirán siendo factores de riesgo que incentiven la migración internacional de dichos profesionales hacia Estados Unidos, situación que acentuará el déficit en México.

El objetivo de este trabajo es dimensionar el número de profesionales de la salud (médicos, enfermeras y en ocupaciones relacionadas con el cuidado de la salud) nacidos en México que viven en Estados Unidos. Asimismo, interesa indagar acerca de cuántos de ellos se emplean en ocupaciones distintas a la salud, quiénes están inactivos o desempleados y cuáles son las características de los subempleados (es decir, de aquellos con una ocupación no profesional). En un contexto de déficit se esperaría que dichos indicadores fuesen bajos, aun entre los inmigrantes.

En un primer momento, el análisis aborda la magnitud del déficit de profesionales de la salud en México y en Estados Unidos y el grado de envejecimiento que experimentan ambas naciones. Posteriormente presenta una estimación de la magnitud de la inmigración de mexicanos en áreas y ocupaciones de la salud, 
así como de los flujos que ingresan por año. Por último, examina su condición de actividad y hace un análisis multivariado de algunos factores que inciden en el desempleo y la inactividad, el subempleo o el cambio de campo ocupacional.

\section{Antecedentes metodológicos y fuentes de información}

La población objetivo es la nacida en México de 22 a 70 años de edad y que reside en Estados Unidos con estudios superiores en áreas relacionadas con la salud. Se utilizan datos estadísticos de la Organización Panamericana de la Salud (OPS, 2013), y la OMS. La estadística presentada se estima para los mexicanos residentes en Estados Unidos con la American Community Survey (ACS, 2016), cuyo objetivo es proveer información de los cambios en las características sociodemográficas y económicas de la población a través del tiempo. El tamaño de muestra permite obtener estimaciones estadísticas confiables para grupos subnacionales.

En el caso de los residentes en México, las estimaciones se llevan a cabo con la Encuesta Nacional de Ocupación y Empleo (ENOE) 2016 del Instituto Nacional de Estadística, Geografía e Informática (INEGI); su propósito es obtener información estadística sobre las características ocupacionales de la población, junto con otras variables demográficas y económicas que hacen factible profundizar en el análisis de los aspectos laborales.

El análisis se apoya en metodologías de naturaleza descriptiva y multivariada. Específicamente, mediante el modelo logit binomial se examina la probabilidad relativa de: 1. Estar desempleado/inactivo. 2. Ocupado en actividades no profesionales. 3. En una ocupación distinta al área de la salud. La finalidad es observar las características individuales de quienes tendrían mayor probabilidad relativa de encontrarse en alguna de esas situaciones. Las variables independientes del modelo son sexo, edad, nivel de escolaridad, área de conocimiento, dominio del idioma inglés, tipo o país de formación académica, ciudadanía, periodo de ingreso a Estados Unidos y situación conyugal. La estimación del tipo o país de formación académica se basa en la metodología de Gaspar Olvera (2016). 


\section{La migración de profesionistas en el marco del capitalismo contemporáneo: consideraciones teóricas y conceptuales}

En un trabajo previo se advertía que

la exportación directa de la fuerza de trabajo por la vía de la migración laboral implica la transferencia de los beneficios futuros anticipados que surgen de los gastos formativos y de reproducción social de la fuerza de trabajo que emigra. Estos costos - como se ha demostrado para el caso de México, principal país expulsor de emigrantes del mundo - no son compensados por el flujo de remesas. En términos demográficos, esta transferencia significa - para países periféricos que se ubican en un estadio avanzado de la transición demográfica - la exportación de su bono demográfico, es decir, la población en edad productiva que sirve de soporte para el sostenimiento de la población infantil y los adultos mayores. En un sentido más profundo, esta transferencia implica la pérdida del más importante recurso para la acumulación de capital en el país de origen: su fuerza laboral (Delgado y Gaspar, 2018:178).

Esta postura se fundamenta en la premisa de que el contexto en el que se despliega la migración contemporánea nada tiene que ver con el mito y la ideología de «libre mercado», fundamento de las posturas neoclásicas. En contraste, se parte de la consideración de que vivimos en una etapa del capitalismo caracterizada por el predominio de las grandes corporaciones multinacionales, situación que acentúa y profundiza las dinámicas de desarrollo desigual y torna al grueso de los desplazamientos poblacionales en migraciones forzadas. En efecto, bajo el capitalismo contemporáneo: a) la migración experimenta cambios cuantitativos y cualitativos de primer orden derivados de la globalización neoliberal; b) no es el mercado el que regula los flujos migratorios (versus la perspectiva neoclásica); c) la migración de profesionistas experimenta cambios cuantitativos y transformaciones de índole cualitativa; d) se despliega un creciente contingente de posgraduados en áreas de CTIM asociado a una reestructuración de los sistemas de innovación a escala global; y e) no obstante la creciente demanda de científicos y tecnólogos provenientes de los países periféricos y emergentes, la migración de profesionales de la salud continúa siendo significativa, resaltada por el envejecimiento de la población y la emergencia de nuevas enfermedades en los países más desarrollados. 
Ante tales circunstancias, la migración de profesionales de la salud no ha dejado de manifestarse como un fenómeno creciente y dinámico que impone complejos desafíos a las instituciones y a los sistemas de salud. Su complejidad se asocia al papel que desempeñan los países, ya sea como receptores, expulsores o una combinación de ambos. Una particularidad de la migración de profesionales de la salud es que se circunscribe a un marco regulatorio en materia de formación y ejercicio profesional, además de una política migratoria de los países avanzados que promueve la migración de sus profesionales y la movilidad de sus estudiantes (OPS, 2013).

A fin de comprender las causas de la migración de profesionales de la salud, su inserción laboral y su práctica profesional, es importante recurrir — sin perder de vista las causas estructurales de la migración contemporánea- a elementos de la teoría del capital humano institucionalizado, la cual hace referencia a la educación formal y a los títulos profesionales que certifican el término de las diferentes etapas de la misma (Bourdieu, 2001).

El modelo de la competencia por los puestos de Lester C. Thurow (1975) se basa en las competencias observables de las personas para ser seleccionadas: serán las personas más productivas y que requieran menor inversión en capacitación las que ocupen los puestos ofertados; en esa perspectiva, la fuerza de trabajo migrante ofrece claras ventajas. De ese modo, los profesionales de la salud más capacitados podrán acceder o competir por una migración laboral que les garantice mejores salarios y condiciones laborales relativamente aceptables. Azqueta, Gavaldón y Margalef (2007) explican que otro factor menos estudiado es el efecto que tiene el capital social en la movilidad ocupacional e indican que éste no necesariamente depende de la disponibilidad o grado de habilidades y conocimientos del individuo, sino de la consolidación de redes sociales. Burgos y López (2010:22) enuncian otros postulados teóricos que permiten entender la situación del mercado laboral profesional, como son los correspondientes a la asignación y el conocimiento heterogéneo; ambos comparten la idea central de que las retribuciones se determinan por el nivel educativo del individuo y por las características del puesto de trabajo; la diferencia entre una y otra «está en la relación que observan entre la sobreeducación (desfase de educación) y a la subutilización de conocimientos y habilidades (desfase de conocimientos), siendo la teoría del conocimiento heterogéneo o de correspondencia la que hace una clara distinción entre ambos conceptos».

Basch (2003) aclara que la investigación sobre el tema ha hecho hincapié en los factores que alientan la expulsión y la atracción, con énfasis en el diferencial 
salarial. Advierte además que al centrarse sólo en ese modelo se corre el riesgo de minimizar el papel de las instituciones en la generación y sostenimiento de la migración internacional, al tiempo que se excluye la influencia de los Estados que participan activamente en la economía global para promover el empleo en el extranjero, como ocurre en Filipinas con los médicos y enfermeras. Se insiste en la relevancia de considerar redes y vínculos sociales, que fomentan una mayor migración al reducir costos y riesgos del proceso migratorio. Ello supone que, una vez establecidas las rutas migratorias, el fenómeno tiende a perpetuarse a través de redes y vínculos sociales que funcionan como capital social (Díaz, 2018).

La migración de profesionales de la salud puede constituirse como un instrumento de desarrollo para el sistema de salud y la cooperación científica en México, al igual que un obstáculo para el mismo y agudizar de esa manera el problema de déficit. La Association of American Medical Colleges (AAMC) indica que los graduados internacionales en Estados Unidos representan 25 por ciento del grupo de médicos, los cuales tienen visa de estudiante, de visitante, de intercambio o de empleo, la mayoría busca el estatus de ciudadano una vez que su residencia está completa, lo que transforma su movilidad en una migración. Datos de la OCDE (2015) revelan que hay 10 mil 593 médicos mexicanos formados en el extranjero, principalmente en Estados Unidos (10 mil 214 médicos). Entre los posgraduados mexicanos que realizaron estudios en ciencias de la salud en Estados Unidos, 55.6 por ciento tenía planes definitivos de quedarse para realizar un posdoctorado o porque contaba con un trabajo pactado. La migración puede ser un incentivo positivo y significativo para la formación de futuros médicos, pero de débil magnitud; es decir, el número de doctores que migran nunca será compensado por el número de personas en formación (Bhargava et al., 2011, citado en Yasser y Bourgueil, 2014).

Entonces, la migración de profesionales de la salud de México encuentra su explicación en las dinámicas de desarrollo desigual generadas entre el país de origen y el de destino. A contrario sensu de la economía neoclásica, las asimetrías entre países y los diferenciales salariales derivados del arbitraje laboral global (Delgado y Martin, 2015) se explican en parte porque las personas participan en los flujos migratorios, incluso cuando son subvaloradas sus capacidades en el destino.

La migración internacional de los profesionales de la salud no sólo tiene repercusiones para los sistemas económicos y de salud de los países involucrados, también para los propios migrantes. No todos los migrantes con estudios en áreas de la salud logran incorporarse al mercado laboral de la salud o al calificado en 
el destino, emplearse o percibir ingresos por su trabajo similares a los que recibe la población nativa. Los inmigrantes pueden experimentar desvalorización de sus capacidades o abuso en el mercado laboral del país anfitrión. Asimismo, cuando retornan a su país de origen y no logran ocuparse o emplease en puestos adecuados a su nivel de calificación y experiencia adquirida fuera de su país, situación que puede detonar una re-emigración. Las personas calificadas o con estudios superiores que trabajan en empleos no calificados, en subempleo, con bajos salarios o desempleadas; es lo que se conoce, en términos meramente descriptivos, como desperdicio de cerebros (Batalova, Fix, Mittelsadt y Marek, 2016).

Cabe destacar que la falta de acuerdos entre Estados Unidos y México para certificar y otorgar equivalencias a los títulos profesionales hace que los salarios obtenidos por los inmigrantes mexicanos con estudios superiores tiendan a ser bajos y que su inserción ocupacional no corresponda, en muchos casos, a su experiencia y nivel de estudios (Giorguli y Gaspar, 2008). Aun con correspondencia entre nivel de calificación y ocupación puede existir brain abuse, cuando los ingresos que perciben por su trabajo son inferiores a los que obtiene la población nativa del destino; la paradoja de esta situación es que incluso esos ingresos son superiores a los que obtendrían en sus países de origen.

En el contexto de la globalización neoliberal, los flujos migratorios han experimentado cambios sustanciales que profundizan las dinámicas de desarrollo desigual en el horizonte Norte-Sur o centro-periferia, lo cual guarda relación con los cambios demográficos y epidemiológicos de las naciones más desarrolladas y crecientemente envejecidas (OIM, 2013). El número de personas que viven fuera de su país de nacimiento se ha multiplicado y las remesas familiares que generan los migrantes han alcanzado niveles sin precedentes. Ello no significa, sin embargo, que la migración figure como subsidio Norte-Sur y una avenida para el desarrollo de los países de origen, como lo postulan el Banco Mundial y las principales potencias capitalistas. Los patrones de origen-destino de los migrantes laborales y no laborales, calificados o no, describen la cambiante geografía de la migración y la creciente dificultad — derivada de las políticas xenófobas y criminalizadoras imperantes - para atacar las causas de raíz de la migración forzada. 


\section{El déficit de profesionales de la salud en México y Estados Unidos}

Entre los países avanzados, Estados Unidos destaca como destino principal de la migración laboral en áreas de la salud, seguido de Italia, Francia, Polonia y Reino Unido. Estos cuatro países encabezan la lista de los 10 países con el índice de envejecimiento más alto. México se sitúa en la sexta posición entre los principales países de origen que proveen de doctores a Estados Unidos, toda vez que en las primeras posiciones se encuentran India, Pakistán, Granada y Filipinas.

En la década de 1970 Estados Unidos tenía indicios de escasez de médicos, en la actualidad ostenta un fenómeno similar con un proceso acelerado de envejecimiento de su población. La AAMC calcula que la demanda de médicos seguirá creciendo más rápido que la oferta, lo que resulta en un déficit proyectado entre 40 mil 800 y 104 mil 900 médicos para 2030. El déficit proyectado para la atención primaria oscila entre 7 mil 300 y 43 mil 100 médicos; para la atención no primaria entre 33 mil 500 y 61 mil 800, en especial de médicos cirujanos; y se prevé escasez de enfermeras. El estudio añade que los médicos y las enfermeras tienen altas tasas de jubilación, por lo que el envejecimiento poblacional, en tanto variable demográfica, figura como la causa principal de la escasez, actual y previsible, de los profesionales de la salud, en Estados Unidos.

Por su parte, datos de la OCDE (2017:2) muestran que en México el número de médicos y enfermeras está aumentando, pero mantiene niveles bajos en relación con los estándares de la OCDE. De hecho, el gasto en salud, médicos, enfermeras y camas per cápita se encuentra por debajo del promedio de la OCDE. Al respecto, México tiene 2.4 médicos por cada mil habitantes, en comparación con un promedio de 3.4 para la OCDE. En similar tenor, cuenta con menos de un tercio del número de enfermeras y camas de hospital por cada mil habitantes que en promedio poseen los países de dicha organización (véase gráfica 1). 


\section{GRÁFICA 1}

Doctores y enfermeras por cada mil habitantes, 2015

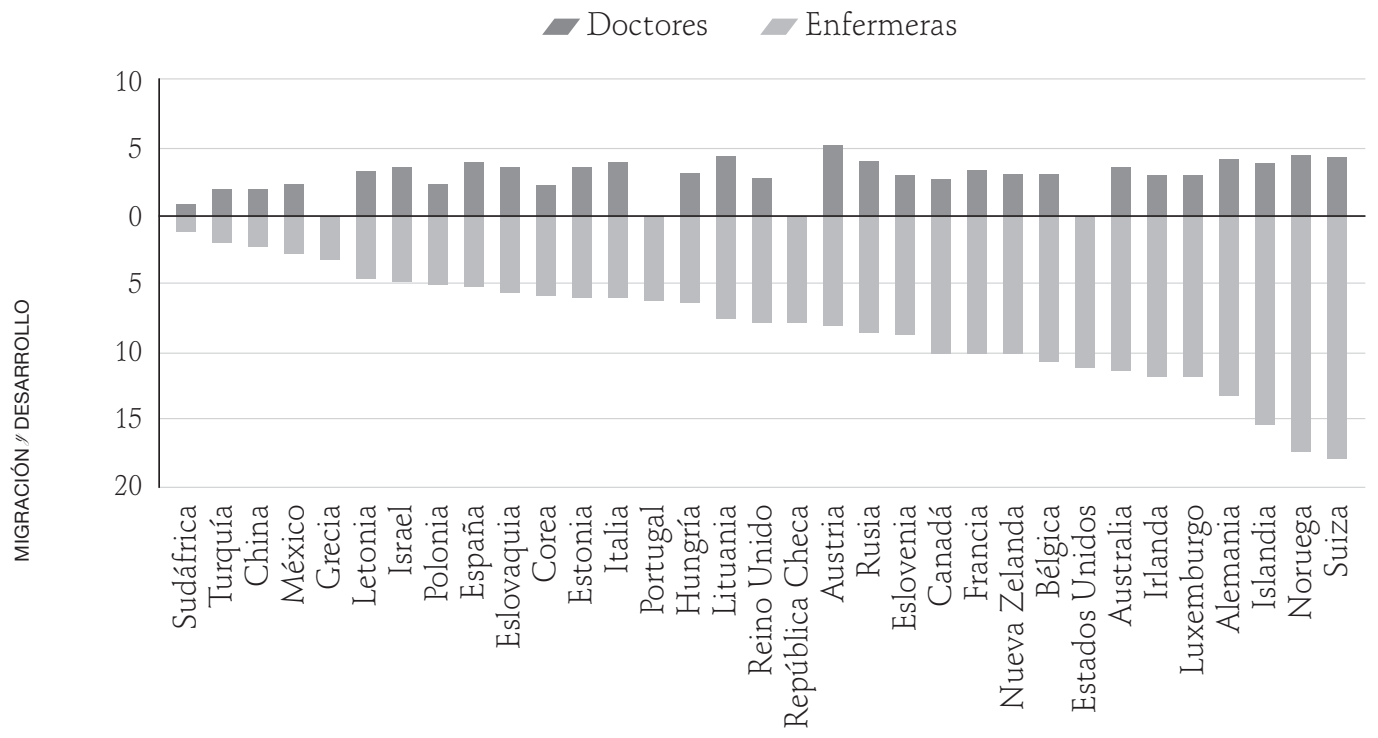

La densidad de médicos y enfermeras es un importante indicador de los recursos humanos disponibles para la atención de la salud, enuncia el nivel de cobertura y hasta cierto punto el nivel de calidad de atención que recibe la población. Información de INEGI (2014) da cuenta de la problemática vinculada con la disponibilidad de recursos humanos en salud que experimenta la gran mayoría de las entidades del país. Concerniente a los médicos, sólo ocho entidades se encuentran por arriba o muy próximas al estándar de médicos por habitante. Por su parte, en enfermeras por habitante, sólo cuatro entidades cumplen los estándares de seis enfermeras por cada mil habitantes (véase gráfica 2).

Debido al déficit de médicos y enfermeras en México, con implicaciones diferenciales en los niveles estatal y local para atender las necesidades internas de salud y atención sanitaria, su migración internacional se configura actualmente como un problema social que puede agravarse en el corto plazo ante el inminente envejecimiento de la población del país y los escasos recursos destinados a la formación de profesionales de la salud, a lo que se añaden condiciones de trabajo insatisfactorias, gestión inadecuada de recursos humanos y limitadas oportunidades para el desarrollo profesional. 
Por tanto, resulta imprescindible reorientar las políticas de gestión y formación de recursos humanos en materia de salud conforme a las necesidades demográficas y epidemiológicas del país, a la vez que se minimizan los efectos negativos de la emigración de recursos humanos en áreas de la salud, la cual es motivada por niveles salariales, estabilidad laboral y posibilidades de desarrollo profesional en otros países. Ello plantea la urgencia de diseñar políticas y estrategias eficaces que favorezcan la atención integral de la problemática de salud de la población, eviten el déficit de estos profesionales y fortalezcan las capacidades de investigación e innovación internas.

\section{GRÁFICA 2}

Déficit de médicos y enfermeras en México por entidad federativa, 2014

Médicos por cada mil habitantes

— Estándar (médicos)
Enfermeras por cada mil habitantes

- Estándar (enfermeras)

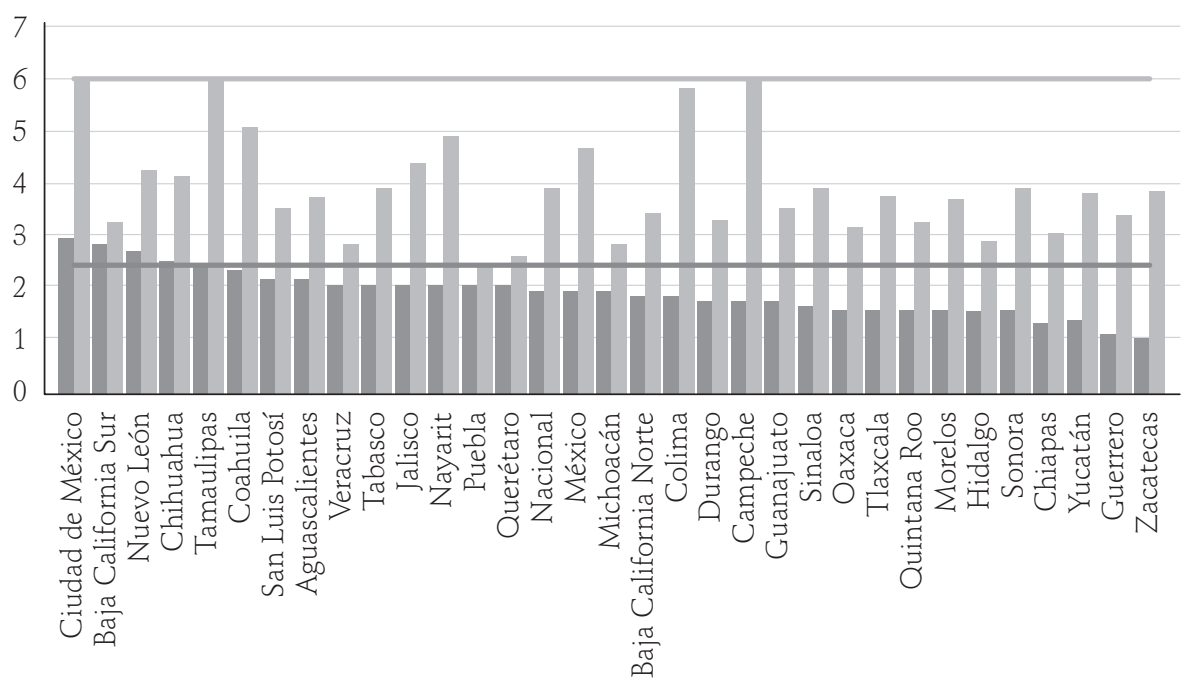




\section{La migración internacional: factor que contribuye al déficit}

La migración de profesionales de la salud es una realidad mundial con tendencia de incremento progresivo (OPS, 2013). La OMS revela que esta emigración en algunas naciones eleva los costos del servicio y acelera el envejecimiento de los profesionales. Asimismo, debido a una diversidad de factores, entre los que destacan el retiro y no reemplazo de puestos, muchas de las plazas vacantes se pierden por restricciones presupuestales. A lo anterior se agrega la presencia de políticas restrictivas en la matrícula correspondiente a tales opciones profesionales, así como la eventualidad de que las oportunidades de empleo no necesariamente se ubiquen en el campo de la salud. Más todavía, es preciso considerar los problemas relacionados con la certificación y la falta de articulación entre formación de personal y las exigencias de los sistemas de servicios de salud, lo que deriva, como refiere la $\mathrm{OCDE}$, en la ausencia de profesionales de la salud con habilidades correctas en los lugares apropiados (OPS, 2006; OCDE, 2016).

Cabe aclarar que se reconocen ciertos beneficios de esta migración para el desarrollo de los países de origen, siempre y cuando el migrante o estudiante regrese y aplique las habilidades adquiridas en el exterior, y de ese modo promueva el fortalecimiento del sistema de salud doméstico (OPS, 2006). En México, la migración hacia Estados Unidos surge por diversas causas estructurales, pues numerosos inmigrantes mexicanos con conocimiento en áreas de la salud —como se verá más adelante- están subvalorados en relación con sus capacidades o se encuentran desempleados o inactivos, particularmente aquellos con estudios de licenciatura. Ello permite suponer que no se trata de una política pública explícita de promoción de la migración como sucede en Filipinas, India y algunos países de África.

Además, los migrantes con estudios superiores de licenciatura y posgrado, incluidos los profesionales y técnicos de la salud, entran en el proceso de la migración orillados por condiciones laborales adversas en sus países de origen o son reclutados y motivados por las políticas de atracción que ejercen los países de destino (OPS, 2013). En ese contexto globalizado los migrantes profesionales de la salud enfrentan desigualdades en términos de género, etnia y clase (Bailey y Mulder, 2017). También enfrentan barreras para ingresar al mercado laboral calificado a causa de la subvaloración de sus credenciales y aquellas derivadas de la falta de certificación y equivalencia de títulos, o por una situación de irregularidad en su estatus de residencia. 


\section{Profesionales de la salud en Estados Unidos}

Con el propósito de dimensionar el número de mexicanos en Estados Unidos dedicados a la atención de la salud con estudios de grado asociados a licenciatura o posgrado se utiliza la información sobre área de conocimiento y ocupación. La variable de ocupación hace factible distinguir a los mexicanos que tienen estudios en áreas distintas a la salud pero que se emplean en ese campo.

Los prestadores de servicios de origen inmigrante cumplen un papel importante para garantizar el funcionamiento del sistema de salud en Estados Unidos. Por ejemplo, uno de cada cinco profesionales con carreras en áreas de la salud u ocupados en campos de la salud es inmigrante. Filipinas, India, China y México encabezan la lista de los principales proveedores, con 324 mil, 210 mil, 90 mil y 67 mil profesionales respectivamente. Aunque el volumen de inmigrantes mexicanos es 4.9 veces inferior al de Filipinas y 3.2 veces inferior al de India, el stock muestra una tendencia creciente desde 2010. El número de inmigrantes mexicanos con estudios superiores ocupados en gerentes de servicios médicos y de salud, ciencias médicas, médicos y auxiliares de la salud pasó de 24 mil a 72 mil entre 2000 y 2016, lo que significa que en ese lapso el número se triplicó. De los ocupados en 2016, 30 mil tienen grado asociado a licenciatura, los restantes 42 mil poseen estudios de licenciatura o posgrado. En 2009 el cuestionario de la ACS incluyó la pregunta de área de conocimiento para los que cuentan con estudios de licenciatura o posgrado, pero el área reportada corresponde al grado de licenciatura. Según esta limitación, se estima que en 2009 había 24 mil inmigrantes mexicanos con estudios de licenciatura o posgrado en áreas del conocimiento en medicina y ciencias de la salud, cifra que asciende a 39 mil en 2016, lo que equivale a un incremento de 62.7 por ciento (gráfica 3). Datos más recientes de 2018 indican que el número de inmigrantes mexicanos con estudios superiores en áreas de la salud u ocupados en campos de la salud asciende a casi 106 mil, 34 mil más que en 2016. 


\section{GRÁFICA 3}

Inmigrantes mexicanos en áreas y ocupaciones relacionadas con la salud (stock), de 2000 a 2018

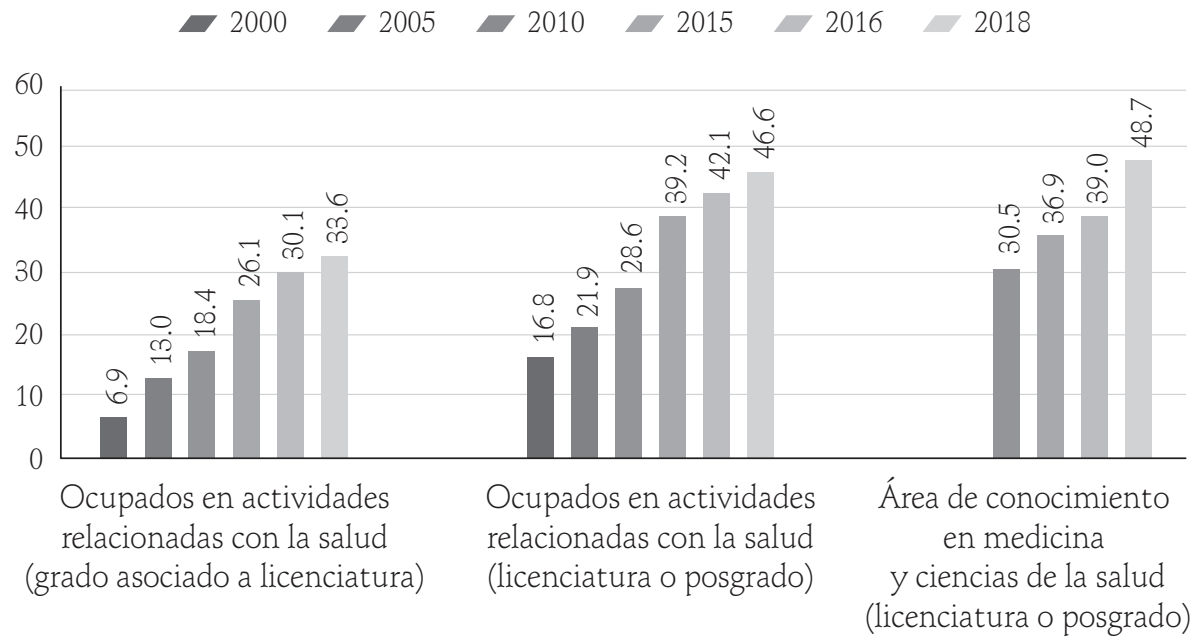

Fuente: estimación propia con base en U.S. Census Bureau, American Community Survey (ACS) 2000, 2005, 2010, 2015, 2016 y 2018. Incluye a la población de 22 años o más de edad con estudios superiores.

Por área de conocimiento, más de 39 mil inmigrantes mexicanos que residen en Estados Unidos tienen carreras en áreas de medicina y ciencias de la salud, de los cuales 74.2 por ciento posee estudios de licenciatura y 25.8 por ciento de posgrado. Casi 24 mil (61.1 por ciento) son de enfermería y de estos últimos 82.5 por ciento son mujeres. Por ocupación, más de 72 mil inmigrantes mexicanos realizan alguna actividad vinculada con el cuidado de la salud, 42.1 por ciento cuenta con estudios de grado asociado a licenciatura, 34.8 por ciento de licenciatura y 23.1 por ciento de posgrado. La mayor proporción son médicos (65.5 por ciento) y auxiliares de la salud (26.5 por ciento). Entre los que tienen posgrado, 15.5 por ciento son gerentes de servicios de salud, 71.5 por ciento médicos y 12.4 por ciento auxiliares de la salud (cuadro 1). 


\section{CUADRO 1}

Inmigrantes mexicanos en áreas del conocimiento y ocupaciones relacionadas con el cuidado de la salud por tipo y nivel de escolaridad, 2016

\begin{tabular}{|c|c|c|c|c|c|c|c|c|c|}
\hline & & $\begin{array}{l}\text { reas en } \\
\text { encias }\end{array}$ & $\begin{array}{l}\text { nedicino } \\
\text { e la salt }\end{array}$ & & & $\begin{array}{l}\text { Ocupa } \\
\text { con áreas }\end{array}$ & $\begin{array}{l}\text { iones en } \\
\text { tjenas }\end{array}$ & $\begin{array}{l}\text { alud } \\
\text { a salud }\end{array}$ & \\
\hline 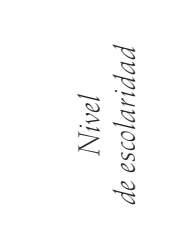 & 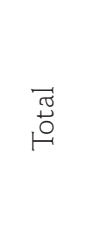 & 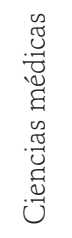 & 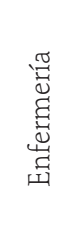 & 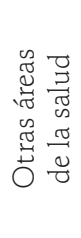 & 营 & 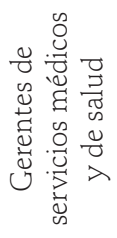 & 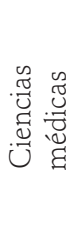 & 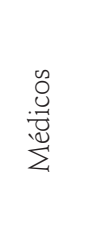 & 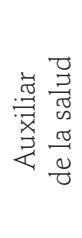 \\
\hline $\begin{array}{l}\text { Grado asociado } \\
\text { a licenciatura }\end{array}$ & & & & & 30.4 & 1.4 & 0.0 & 16.7 & 12.4 \\
\hline Licenciatura & 29.0 & 1.1 & 19.7 & 8.2 & 25.2 & 1.3 & 0.4 & 18.7 & 4.7 \\
\hline Posgrado & 10.1 & 0.0 & 4.1 & 5.9 & 16.7 & 2.6 & 0.1 & 12.0 & 2.1 \\
\hline Total (miles) & 39.0 & 1.1 & 23.8 & 14.1 & 72.4 & 5.3 & 0.5 & 47.4 & 19.1 \\
\hline $\begin{array}{l}\text { Grado asociado } \\
\text { a licenciatura }\end{array}$ & & & & & $42.1 \%$ & $4.5 \%$ & $0.0 \%$ & $54.9 \%$ & $40.6 \%$ \\
\hline Licenciatura & $74.2 \%$ & $3.7 \%$ & $68.0 \%$ & $28.3 \%$ & $34.8 \%$ & $5.4 \%$ & $1.6 \%$ & $74.3 \%$ & $18.7 \%$ \\
\hline Posgrado & $25.8 \%$ & $0.0 \%$ & $41.1 \%$ & $58.9 \%$ & $23.1 \%$ & $15.5 \%$ & $0.5 \%$ & $71.5 \%$ & $12.4 \%$ \\
\hline Total & $100 \%$ & $2.7 \%$ & $61.1 \%$ & $36.2 \%$ & $100 \%$ & $7.3 \%$ & $0.7 \%$ & $65.5 \%$ & $26.5 \%$ \\
\hline
\end{tabular}

Fuente: estimación propia con base en U.S. Census Bureau, American Community Survey (ACS), 2016.

En México, 9.1 por ciento de los mexicanos con licenciatura o posgrado tiene estudios en áreas de medicina y ciencias de la salud (10 mil 449 de 954 mil) y en Estados Unidos hay 39 mil inmigrantes mexicanos con licenciaturas en esas áreas. Si se considera a los que residen en México (954 mil) y a los que viven en Estados Unidos (39 mil), la relación por nivel de escolaridad sería de 3.3 por ciento entre los que cuentan con estudios de licenciatura y 8.2 por ciento con posgrado. El grupo más numeroso de inmigrantes mexicanos en Estados Unidos con estudios en áreas de la salud corresponde a los de enfermería (61.1 por ciento, 42 mil). En México, poco más de 329 mil mexicanos estudiaron enfermería, lo que sugiere que 6.7 por ciento reside en Estados Unidos. Por nivel de escolaridad esa relación es de 5.7 por ciento para los que cuentan con licenciatura y de 50.5 por ciento para los que tienen posgrado.

Se han establecido dos condiciones primordiales en la aplicación del término «fuga de cerebros» a un país. En primer lugar, debe haber una pérdida significativa 
de su población calificada o altamente calificada, la cual ocurre cuando el porcentaje de la migración supera 10 por ciento. En segundo lugar, esa pérdida debe provocar consecuencias económicas adversas (Lowell, Findlay y Stewart, 2004; Tigau, 2015). De acuerdo con ese enfoque, la fuga de cerebros ocurriría sólo entre los mexicanos con posgrado en enfermería (se acercaría en otras áreas con posgrado). No obstante, el número de inmigrantes en esas áreas de conocimiento muestra una tendencia creciente en los niveles de escolaridad analizados. Si bien el número de posgraduados en áreas de la salud es menor al de los que tienen licenciatura el peso relativo es mayor, 8.2 por ciento de los mexicanos con posgrado en áreas de la salud reside en Estados Unidos; de manera que México se encuentra ante un déficit de este tipo de profesionales, situación que entraña implicaciones económicas, sociales y humanas (gráfica 4).

\section{GRÁFICA 4}

Peso relativo de los inmigrantes mexicanos con estudios superiores en áreas de la salud en Estados Unidos respecto de los residentes en México, 2016

64

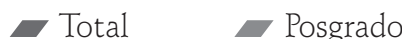
Licenciatura

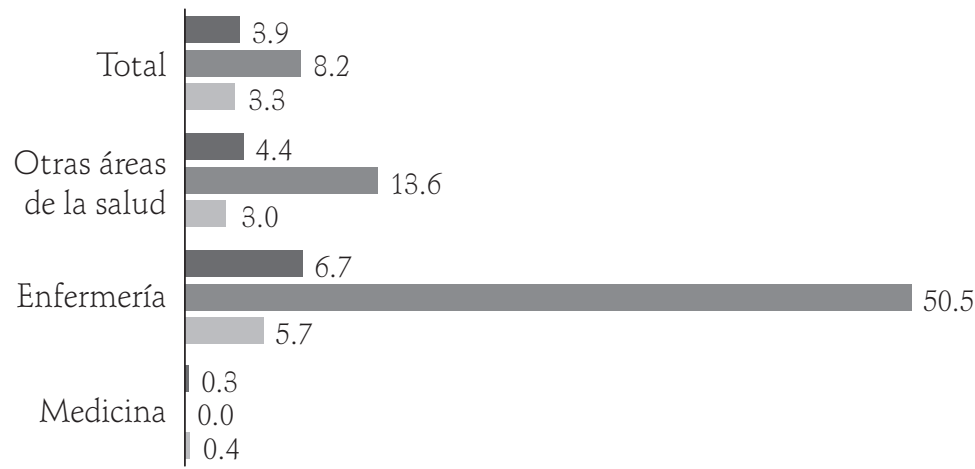

Incluye: programas multidisciplinarios o generales, estomatología y odontología, diagnóstico médico y tecnología del tratamiento, terapia y rehabilitación, farmacia, salud pública, programas de nueva creación del campo de salud. Fuente: estimación propia con base en ACS 2016 y ENOE 2016.

Datos estimados a partir de la encuesta a exbecarios del Consejo Nacional de Ciencia y Tecnología (Conacyt) y miembros del Sistema Nacional de Investigadores (SNI) en el extranjero ratifican a Estados Unidos como el principal destino de los profesionales de México en áreas de medicina y ciencias de la salud. En al 
menos 35 países se encuentra un mexicano con estudios en áreas del conocimiento de la salud; en orden de importancia resaltan España, Reino Unido, Alemania, Canadá y Francia. Pese a que esta información subestima su número y presencia fuera del país, da cuenta de la importancia de esa emigración para México, en cuanto a la atención de la población, para los sistemas de innovación y la investigación médica. ${ }^{2}$

Con la finalidad de aproximarse al flujo de emigrantes que logró ingresar y permanecer en Estados Unidos, en una muestra de corte transversal se utilizó la variable del año en que ingresó el inmigrante mexicano a Estados Unidos. Datos de la ACS 2016 indican que entre 2010-2016 entraron anualmente 875 inmigrantes mexicanos con estudios superiores que laboran en una ocupación vinculada con la salud, mientras que los que tienen estudios en áreas del conocimiento relacionadas con la salud ingresaron en promedio 732. Los flujos trianuales estimados con la variable de año de ingreso muestran una tendencia creciente para el periodo referido, aunque a niveles inferiores a los observados antes de la crisis económica de 2007-2009 y similares a los del periodo 1995-2001 (gráfica 5).

\section{GRÁFICA 5}

Flujos trianuales. Inmigrantes mexicanos con carreras en áreas del conocimiento y en ocupaciones relacionadas con la salud, 1980-2017

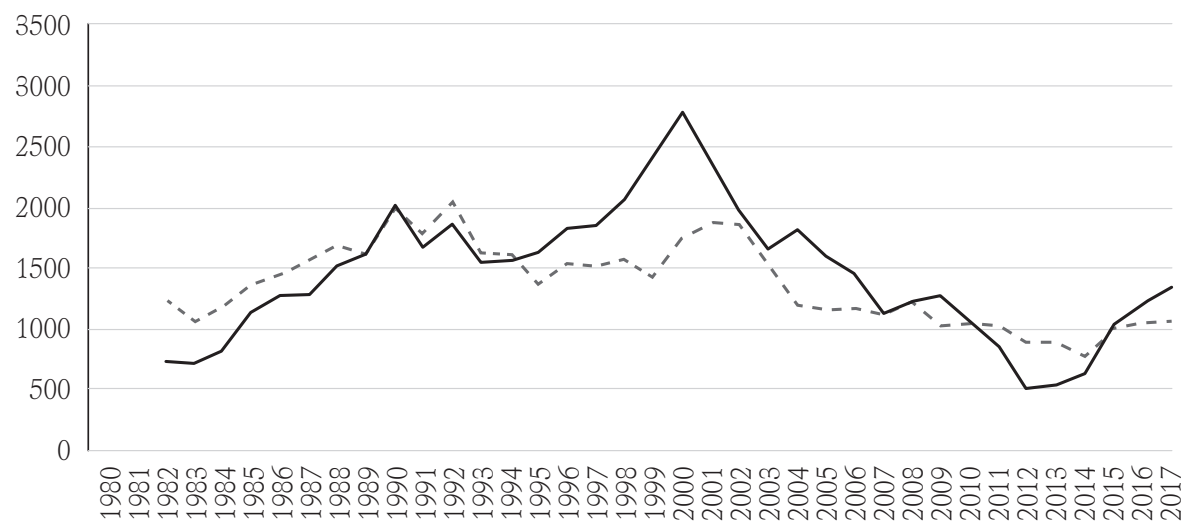

Fuente: estimación propia con base en U.S. Census Bureau, American Community Survey (ACS), 2016 y 2017. Incluye a la población de 22 años o más con estudios superiores de licenciatura o posgrado.

${ }^{2}$ Datos estimados con la encuesta a exbecarios y SNI en el extranjero realizada como parte del proyecto coordinado por Raúl Delgado Wise titulado "La migración altamente calificada: elementos para una política nacional de ciencia y tecnología», financiado por el Conacyt. 
Por un lado, la inmigración de mexicanos profesionales de la salud en Estados Unidos muestra una tendencia creciente. Por el otro, las proyecciones de empleo 2016-2026 indican que entre las ocupaciones que requieren estudios de licenciatura, la de mayor crecimiento absoluto será Enfermería con un salario promedio de 70 mil dólares anuales; con maestría figura también Enfermería (104 mil dólares) y médicos asistentes (105 mil dólares); con doctorado o grado profesional aparecen fisioterapeutas (87 mil dólares), profesores de especialidades de salud (98 mil dólares), instructores y profesores de enfermería (71 mil dólares). Los inmigrantes mexicanos en áreas u ocupaciones de la salud ganan en promedio 482 pesos por hora; los profesionistas del cuidado de la salud y técnicos, 635 pesos por hora; en ocupaciones de apoyo para la atención de la salud, 305 pesos por hora; en ocupaciones profesionales en campos distintos a la salud, 572 pesos por hora. Aun entre los que se emplean en ocupaciones no profesionales el salario por hora es de 274 pesos, superior en todos los casos a los que obtendrían en México.

En México, el salario promedio por hora de los mexicanos en áreas de conocimiento u ocupaciones de la salud es de 79 pesos (INEGI, 2014), seis veces inferior al ingreso promedio por hora del conjunto de inmigrantes mexicanos en áreas de la salud (482 pesos por hora). Estos resultados perfilan una demanda importante de profesionales de la salud en Estados Unidos y los salarios que ofrecen seguirán siendo un incentivo para los migrantes mexicanos.

Sin perder de vista las causas estructurales de la problemática, los resultados permiten ubicar a la inmigración mexicana hacia Estados Unidos con estudios en áreas de la salud en la categoría de migrantes motivados por mejores ingresos. Si bien en el país la tasa de desempleo, de inactividad, así como el porcentaje de profesionales de la salud en ocupaciones ajenas a su profesión y el porcentaje en ocupaciones no profesionales son inferiores a los que exhiben los inmigrantes mexicanos en Estados Unidos (como se puede constatar a continuación) es pertinente analizar este fenómeno con ciertas reservas a fin de no caer en una conclusión simplista y superficial.

\section{Paradoja de los profesionales de la salud}

En efecto, en las naciones con déficit de prestadores de servicios de salud es paradójico que no todos los que tienen estudios en áreas del conocimiento en medicina y ciencias de la salud estén ocupados en una actividad relacionada 
con el cuidado de la salud, ni que todos sean económicamente activos o estén ocupados. En un contexto de déficit de profesionales, ya sea en salud o en otras áreas del conocimiento, es importante distinguir a quienes se desempeñan en campos ajenos a su profesión, están subempleados/subvalorados, desocupados o inactivos, pues este grupo de profesionales resulta en una suerte de desperdicio de recursos humanos.

El desempleo obliga a los profesionales a subocuparse y es posible que un descenso en el desempleo encubra un problema de alza del subempleo. Yetter (2013) expone que hay tres tipos de desempleo: 1. Desempleo friccional: trabajadores calificados que requieren más tiempo para encontrar un trabajo de acuerdo a sus habilidades. 2. Desempleo estructural: ocurre cuando no se poseen las habilidades que buscan los empleadores, por ejemplo, los avances tecnológicos también generan desempleo estructural. 3. Desempleo cíclico: sucede cuando la economía se ha desacelerado, se compran menos bienes y servicios, lo que ocasiona que se necesiten menos trabajadores para producir esos bienes y servicios. No se trata, sin embargo, de un simple problema de «funcionamiento eficiente del mercado», como lo pregonan los economistas neoclásicos, sino de un problema mucho más profundo asociado a las contradicciones del capitalismo contemporáneo y a las nuevas y más profundas dinámicas de desarrollo desigual inherentes a él.

La migración de profesionales en las distintas áreas del conocimiento tiene consecuencias diferenciales sobre la sociedad, la economía y el desarrollo de un país; de igual modo, las actividades económicas de la población en edad laboral y las condiciones en que laboran impactan significativamente. Un problema de gran relevancia que plantea la migración internacional de profesionistas de la salud y de otras áreas del conocimiento en la práctica profesional es el reconocimiento de sus títulos académicos y su certificación y equivalencia en el país de destino. Con frecuencia la inmigración de profesionistas enfrenta importantes barreras para su desarrollo profesional, en concreto los que obtuvieron títulos en el extranjero; entre dichas barreras destacan la acreditación y equiparación de títulos profesionales, dificultades para demostrar la experiencia laboral y otras de tipo discriminatorio por origen étnico (Giorguli y Gaspar, 2008; Batalova, Fix y Creticos, 2008; Nejdan, 2010; Rabben, 2013; Gaspar, 2016). Por lo demás, tales factores favorecen el abaratamiento del costo de este servicio en los países desarrollados o centrales y alientan la subvaluación del trabajo calificado de los profesionistas de la salud inmigrantes (Ávila y Gaspar, 2019). 
Las habilidades adquiridas a través de la educación formal entrañan costos individuales y públicos que pueden ser rentables para los individuos y el desarrollo económico de los Estados. Respecto a los inmigrantes con estudios superiores, la rentabilidad de sus credenciales educativas depende, entre otros, de factores demográficos, sociales, del estatus migratorio, características individuales, capital social; así como de la portabilidad, equivalencia, revalidación y reconocimiento de sus credenciales educativas obtenidas por medios formales en sus países de origen y el cumplimiento de las normas que rigen la práctica profesional en sus destinos. Barreras estructurales que se presentan cuando sus credenciales educativas se perciben de menor calidad y por lo tanto no cumplen con los estándares establecidos en el país de destino. Nejdan Yildiz (2010) refiere que en Estados Unidos ninguna autoridad regula el reconocimiento de las credenciales extranjeras; en lugar de ello, existen tres actores que llevan a cabo dicha tarea: instituciones de educación superior, empleadores y consejos estatales de licencias profesionales.

Además de sus títulos académicos, los prestadores de servicios que acreditan su formación en salud deben contar con una licencia para la práctica profesional emitida en el estado en que se desea trabajar. Las licencias son otorgadas por una agencia gubernamental con base en diversos criterios: grado académico, certificado, evaluación, programas de aprendizaje o experiencia laboral. La licencia debe ser renovada periódicamente puesto que autoriza el ejercicio legal de la ocupación; los trámites y costos difieren de estado a estado, al igual que los requisitos de elegibilidad difieren entre inmigrantes y nativos. La investigación centrada en campos relacionados con la salud ha mostrado que las licencias profesionales rígidas impedían que enfermeras y médicos migrantes ejercieran en sus áreas de especialidad o empleo calificado. Así, la falta de licencias y la depreciación de sus credenciales de educación superior afectan a los inmigrantes calificados y a las comunidades que necesitan sus servicios, sin mencionar la pérdida de ingresos fiscales como resultado del subempleo (Presidents' Alliance, 2019). Respecto a las licencias, se ha recomendado: a) utilizar sistemas alternativos que sean menos restrictivos como la certificación voluntaria del Estado («derecho a título») o el registro (archivo de información básica en un registro estatal); $b$ ) que los requisitos de educación y experiencia laboral estén estrechamente vinculados a las preocupaciones de salud pública y seguridad; y c) simplificar trámites y costos, y ampliar la vigencia de las licencias (The White House, 2015). 
En la investigación de Young et al. (2019) se advierte que los inmigrantes mexicanos ocupan la quinta posición con el mayor número de médicos graduados en su país de origen con licencia activa en Estados Unidos: de 9 mil 990 a 10 mil 66 médicos entre 2010 y 2018. En el último año de observación los inmigrantes graduados en medicina representaban 23 por ciento del total, de éstos 5 por ciento provenía de México; los demás eran graduados de la India, el Caribe, Pakistán y Filipinas, por su orden de importancia. Si se considera la cifra de 2018, $10 \mathrm{mil}$ médicos con licencia y 47.4 mil médicos obtenidos con datos ACS para los inmigrantes procedentes de México, tan sólo 21.1 por ciento de los médicos tendría licencia ocupacional (gráfica 6).

Con la finalidad de confirmar el resultado previo se exploró la CPS que informa sobre la tenencia de certificados y licencias para la ocupación legal. A pesar de que la muestra de los inmigrantes mexicanos ocupados en actividades relacionadas con salud es insuficiente, se estima que esa cifra para el conjunto de inmigrantes con estudios superiores en ocupaciones relacionadas con la salud es de 72 por ciento y para los nativos de 78.2 por ciento. Sin distinguir la ocupación, el porcentaje de inmigrantes mexicanos con estudios superiores que cuentan con al menos uno de los documentos referidos es de 20.4 por ciento del total; por nivel, 14.3 por ciento con grado asociado a licenciatura, 16.5 por ciento con licenciatura y 38.3 por ciento con posgrado.

Cabe resaltar que se han hecho esfuerzos por eliminar esta barrera en la práctica profesional en al menos nueve estados sin éxito, pues se afecta directamente a casi 30 por ciento de los trabajadores estadounidenses y continúa creciendo en densidad y alcance. Su efecto negativo es mayor entre los inmigrantes, porque quienes cuentan con licencia ocupacional tienen salarios más altos, mayor probabilidad de ser empleados y mejores condiciones laborales (Thornton y Timmons, 2015). De acuerdo con las cifras presentadas, es factible suponer que para los inmigrantes mexicanos la falta de licencias es un factor determinante de su inserción en el mercado laboral estadounidense. 


\section{GRÁFICA 6}

Médicos internacionales con licencia activa en Estados Unidos

y el Distrito de Columbia, 2010, 2012, 2014, 2016 y 2018
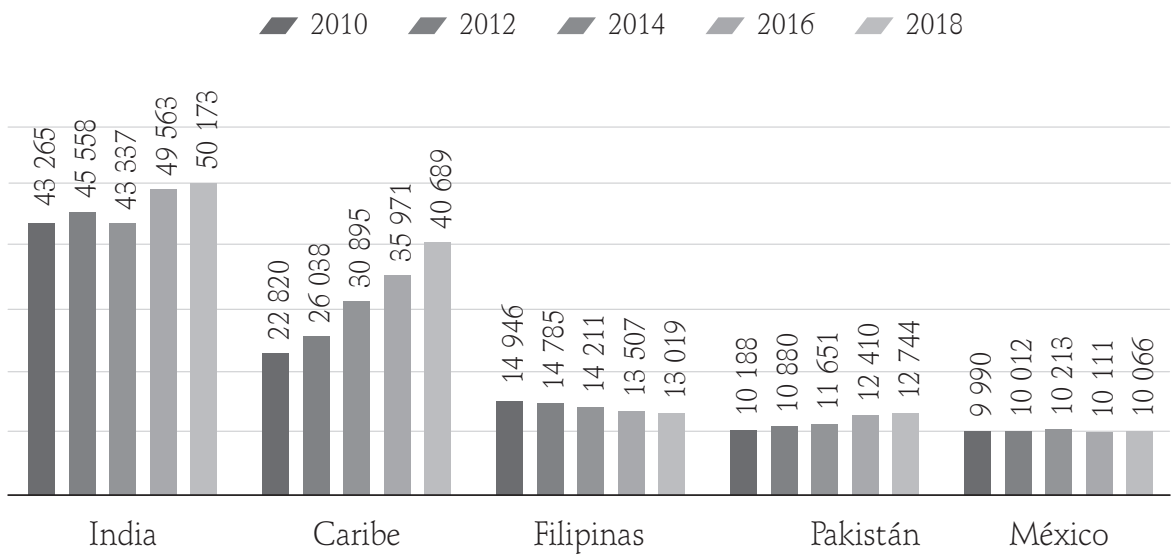

Fuente: elaboración propia con datos del FSMB Census of Licensed Physicians 2010, 2012, 2014, 2016 y 2018.

Para ejemplificar este problema se analiza, concerniente a los que tienen estudios de licenciatura o posgrado, la carrera versus la ocupación y a partir de esta agrupación se examina la condición de actividad por nivel de escolaridad. Se comparan los indicadores de los inmigrantes mexicanos de 22 a 70 años de edad en áreas u ocupaciones relacionadas con la salud que residen en Estados Unidos con la población nativa, con los inmigrantes no mexicanos y con los mexicanos que viven en México. La estimación se lleva a cabo con ACS 2016 y con la Encuesta Nacional de Ocupación y Empleo (ENOE) 2016.

Los indicadores que aparecen en la gráfica 5 revelan el problema de déficit asociado a los prestadores de servicios y a la investigación en salud. La tasa de desempleo de los mexicanos con estudios de licenciatura en áreas de la salud es de 4.9 por ciento, más alta que la que exhibe el conjunto de inmigrantes no mexicanos y los nativos de Estados Unidos y es superior en 2.3 puntos porcentuales respecto de los que viven en México. En un contexto de déficit de profesionales de la salud es importante estudiar las consecuencias del desempleo, una de las más importantes es incentivar la emigración, interna e internacional, y erosionar el capital humano, en particular cuando el desempleo es de largo plazo. Las secuelas del desempleo afectan el entorno más inmediato del individuo y, aunque son producto y resultado de las dinámicas de desarrollo desigual bajo la égida 
neoliberal, tienen efectos de mediano y de largo plazos en el desarrollo económico y social del país (Aparicio, 2006).

La falta de sincronía entre la ocupación ejercida y el área de conocimiento profesional del inmigrante puede acontecer por varias razones. Una de ellas ocurre cuando se encuentra en situación de subempleo, es decir, en un empleo no acorde con el nivel de habilidades o calificación del individuo, circunstancia que también puede constituir un factor que propicia el déficit. En ese tenor, cabe advertir que entre los inmigrantes mexicanos 18.9 por ciento está ocupado en un campo profesional ajeno a su profesión, esa relación es de 14.2 por ciento entre los inmigrantes no mexicanos y de 14.6 por ciento entre los nativos. En contraste, para los que viven en México, dicha falta de correspondencia es de 15.8 por ciento y 15.2 por ciento para los que tienen estudios de licenciatura y posgrado, respectivamente (gráfica 7).

El desempleo y el subempleo estructural obligan a los profesionales a emigrar. Es probable que los mejores salarios ofrecidos en Estados Unidos favorezcan que aun en el subempleo los profesionales de la salud prefieran permanecer en el mercado laboral estadounidense, más allá de su condición laboral relativamente precaria y desvinculada de su campo de conocimiento. La inactividad es alta en el grupo de inmigrantes y nativos con estudios en áreas de conocimiento relacionadas con el cuidado de la salud. A lo anterior se agrega el hecho de que este indicador comprende a la población de 22 a 70 años, lo que entraña una cierta subestimación al dejar fuera a los profesionistas que salen del mercado laboral por jubilación. El desempleo de larga duración, el subempleo y los bajos salarios y malas condiciones laborales pueden conducir a una mayor inactividad.

Asimismo, el porcentaje de profesionistas con carreras de licenciatura en áreas de la salud inmersos en una ocupación no profesional es alto por nivel de escolaridad y grupo de origen, sobre todo entre los inmigrantes mexicanos, cuya proporción es de 35.6 por ciento para los que tienen licenciatura y de 20 por ciento para los que tienen posgrado, proporción muy superior a lo observado entre los inmigrantes no mexicanos y nativos, incluso entre los residentes en México (véase gráfica 6). Una migración perfilada en términos descriptivos como «fuga de cerebros» (es el caso de México), con una alta proporción de calificados subvalorados, se traduce en una forma extrema de desperdicio de capital humano y transferencia de recursos invertidos en educación. Lo que además supone que estos migrantes forman parte de la migración forzada. De acuerdo con Márquez (2010) se trata de una migración forzada debido a que en sus lugares de origen no existen las 
capacidades estructural, institucional y política para retenerlos y promover su desarrollo personal y profesional. Si bien el desempleo y la inactividad derivan en un desaprovechamiento de recursos humanos formados en áreas específicas del conocimiento claves para el desarrollo de la economía y la sociedad en los niveles local, regional y nacional. Este desaprovechamiento repercute en términos individuales para quienes tienen una profesión y se ocupan en actividades afines e incluso no profesionales. Entre los inmigrantes en subempleo, las más de las veces son retribuidos con mejores ingresos y salarios que los que obtendrían en su país de origen. Esa situación deviene en un doble desperdicio de capital humano calificado y de recursos monetarios devengados en educación con impactos negativos de tipo social, económico, institucional e individual.

\section{GRÁFICA 7}

Estados Unidos y México. Indicadores de empleo. Profesionales con estudios superiores en áreas de la salud por nivel de escolaridad, 2016

Tasa de desempleo (por 100) \% en ocupación ajenos a su profesión (salud)
- Tasa de inactividad (por 100)

\% en ocupación no profesionales

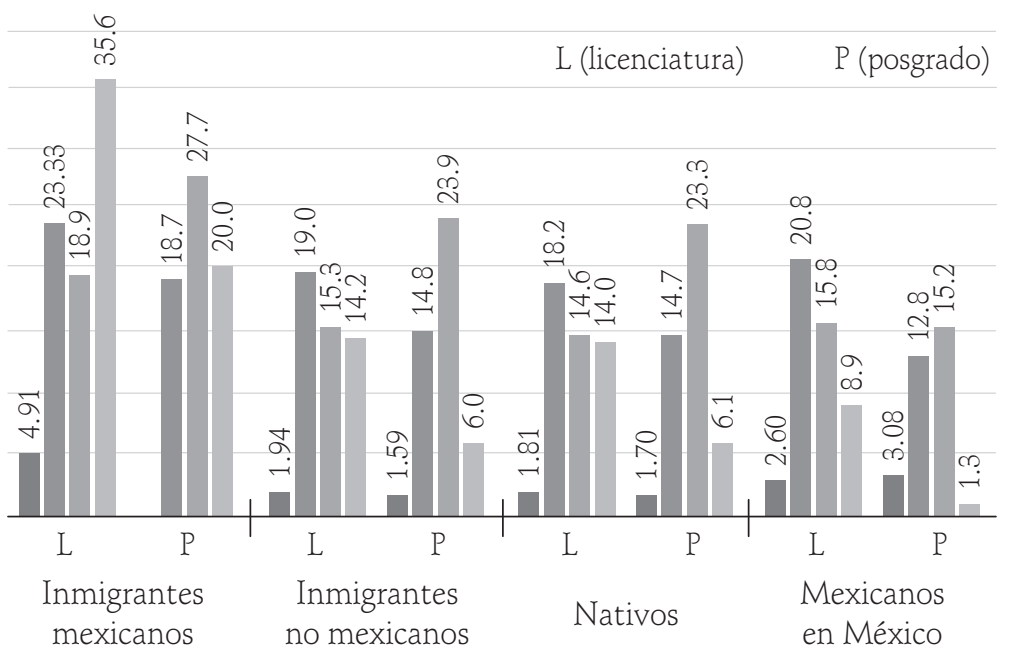

Fuente: estimación propia con base en ACS 2016 y con base en ENOE 2016.

La distribución de los inmigrantes mexicanos con estudios superiores en áreas de la salud corresponde a 25 hombres por cada 100 mujeres; 58.3 por ciento tiene entre 22 y 45 años de edad; 78.7 por ciento habla muy bien y bien el idioma inglés; 
25.5 por ciento posee estudios de posgrado y el restante 74.5 por ciento estudios de licenciatura, 64.2 por ciento tiene estudios en áreas de medicina y enfermería, en mayor proporción son enfermeras. De acuerdo con Batalova, Fix y Bachmeier (2016), contar con un título extranjero en lugar de un título estadounidense disminuye las posibilidades de que los inmigrantes encuentren empleos que coincidan con sus niveles de habilidad, debido a la percepción de la calidad de la educación extranjera y la transferibilidad de las credenciales extranjeras. Gaspar (2016; 2017) encuentra que este resultado no siempre aplica, pues aquellos con estudios de su país de origen y de Estados Unidos, en este último los concluyen (estudios mixtos) y exhiben una mayor probabilidad de estar subempleados respecto de los que tuvieron su formación completa en ese país. Asimismo, el resultado varía según el origen nacional, por ejemplo, los procedentes de India, Corea y Japón, cuya integración laboral es más favorable independientemente del país de estudio. Entre los inmigrantes con estudios en áreas de la salud, 49.8 por ciento realizó estudios en México y 25.0 por ciento en ambos países (estudios mixtos); 55.1 por ciento adquirió la ciudadanía estadounidense y 85.1 por ciento es de largo arribo.

La estadística del cuadro 2 permite observar que quienes cambian de campo de aplicación o están subempleados en una ocupación no profesional se enfrentan a factores de desventaja en comparación a quienes se emplean en su campo de estudio, aunque esas desventajas no explican ese comportamiento. Los datos descriptivos parecen indicar que quienes cambian de campo de aplicación o están subempleados presentan características similares: hay una proporción más alta de profesionales de la salud entre 46 a 70 años de edad; se trata de un grupo más envejecido y se esperaría que contara con mayor experiencia laboral, una proporción menor tiene dominio del inglés y estudios de posgrado. En suma, tales grupos detentan una proporción mayor de individuos con características que los ponen en desventaja respecto de los que se ocupan en su campo de aplicación. 


\section{CUADRO 2}

Características seleccionadas de la población inmigrante mexicana con estudios superiores en áreas de conocimiento en salud. Población de 22 a 70 años de edad

Tipo de ocupación

\begin{tabular}{|c|c|c|c|c|}
\hline & $\begin{array}{l}\text { Relacionadas } \\
\text { con la salud }\end{array}$ & $\begin{array}{c}\text { Otras ocupaciones } \\
\text { profesionales }\end{array}$ & No profesionales & Total \\
\hline Índice de masculinidad & $30 \%$ & $17 \%$ & $25 \%$ & $25 \%$ \\
\hline \multicolumn{5}{|l|}{ Grupo de edad } \\
\hline 22 a 45 años & $59.8 \%$ & $54.2 \%$ & $60.4 \%$ & $58.3 \%$ \\
\hline 46 años o más & $40.2 \%$ & $45.8 \%$ & $39.6 \%$ & $41.7 \%$ \\
\hline $\begin{array}{l}\text { Habla muy bien } \\
\text { y bien inglés }\end{array}$ & $91.4 \%$ & $69.2 \%$ & $70.2 \%$ & $78.7 \%$ \\
\hline Posgrado & $32.5 \%$ & $26.1 \%$ & $14.9 \%$ & $25.5 \%$ \\
\hline \multicolumn{5}{|l|}{ Área de conocimiento } \\
\hline Medicina y enfermería & $69.9 \%$ & $60.8 \%$ & $59.6 \%$ & $64.2 \%$ \\
\hline Otras áreas de la salud & $30.1 \%$ & $39.2 \%$ & $40.4 \%$ & $35.8 \%$ \\
\hline \multicolumn{5}{|l|}{ País de estudio } \\
\hline $\begin{array}{r}\text { Estudios } \\
\text { en Estados Unidos }\end{array}$ & $35.9 \%$ & $22.1 \%$ & $13.4 \%$ & $25.2 \%$ \\
\hline Estudios mixtos & $27.9 \%$ & $21.7 \%$ & $24.1 \%$ & $25.0 \%$ \\
\hline Estudios en México & $36.2 \%$ & $56.2 \%$ & $62.6 \%$ & $49.8 \%$ \\
\hline Ciudadanía & $74.1 \%$ & $47.9 \%$ & $35.5 \%$ & $55.1 \%$ \\
\hline Largo arribo & $88.3 \%$ & $82.5 \%$ & $84.7 \%$ & $85.5 \%$ \\
\hline $\begin{array}{r}\text { Ingreso promedio anual } \\
\text { (dólares) }\end{array}$ & 72,964 & 62,941 & 34,247 & 593 \\
\hline
\end{tabular}

Fuente: estimación propia con base en ACS, 2012-2016.

Para finalizar, se presentan los resultados del análisis multivariado con el propósito de determinar las características de quiénes, entre los inmigrantes mexicanos con estudios profesionales en áreas de la salud, tienen mayor probabilidad relativa de estar: 1. Desempleado o inactivo. 2. En un campo diferente al de la salud. 3. En ocupaciones no profesionales. En los tres modelos solamente se interpretan los resultados estadísticamente significativos y la inferencia se hace manteniendo constante el resto de las variables incluidas en cada modelo. Los estadísticos de bondad de ajuste de cada modelo confirman que se consideraron 
predictores relevantes. Los modelos están correctamente especificados y con un buen ajuste, además de que no presentan problemas de multicolinealidad (véase cuadro 3).

1. El modelo 1 muestra que es más probable para los inmigrantes mexicanos caer en desempleo o inactividad cuando se está empleado en una ocupación no profesional. Dicha característica incrementa la probabilidad relativa de estar en desempleo o inactivo hasta ocho veces, lo que supone que algunos profesionales de la salud prefieren estar desempleados o inactivos antes que aceptar ocuparse en una actividad no profesional y que sólo lo hacen en una situación extrema, pues aceptar desempeñar una actividad no calificada incrementa la probabilidad relativa de ocuparse hasta 3.2 veces. Otras características individuales que favorecen el desempleo o la inactividad son: a) ser mujer, quizá por los patrones tradicionales de género, ya que son mayoría entre los que se encuentran en inactividad; b) no hablar inglés; y c) no tener la ciudadanía estadounidense.

2. Los resultados estadísticamente significativos del modelo 2 , referido a la subvaloración de estos profesionales, indican que es más probable estar en una ocupación no profesional cuando se cuenta con: a) licenciatura en lugar de posgrado; b) estudios en áreas de conocimiento en salud distintas a medicina y enfermería; y c) estudios mixtos, es decir, que comenzaron en México y los concluyeron en Estados Unidos, o la formación académica se realizó en México, en cuyo caso es 1.8 veces superior entre los primeros y 2.8 veces superior entre los segundos, ambos respecto de los que realizaron sus estudios en Estados Unidos. La no ciudadanía estadounidense y ser migrante de reciente arribo propicia la subvaloración.

3. Finalmente, el modelo 3 expone que las características individuales que promueven el cambio del campo ocupacional son: estar desempleado o inactivo, tener estudios de licenciatura, tener estudios en salud en un área distinta a medicina y enfermería, no hablar inglés, haber estudiado en ambos países o en México, carecer de la ciudadanía estadounidense y ser un migrante de reciente arribo.

En los tres modelos existen coincidencias en las características individuales y de capital humano de quienes tienen mayor probabilidad relativa de estar desempleados o inactivos u ocupados en una actividad no profesional, o de cambiar de campo ocupacional. Entre ellas, destacan el dominio del idioma inglés, el nivel de escolaridad, la formación académica en México, este último da una idea del no reconocimiento de títulos profesionales cuando se obtienen en el origen (Batalova, Fix y Creticos, 2008) y de la transferencia de recursos humanos 
calificados y recursos monetarios que hacen a los destinos de los migrantes (Gaspar, 2016; Delgado y Gaspar, 2018). La importancia del tiempo de estancia en Estados Unidos podría relacionarse con la experiencia laboral, el conocimiento del mercado laboral y el fortalecimiento de redes sociales. Entre los predictores resalta la ciudadanía estadounidense como factor que favorece la ocupación, la valoración de títulos o credenciales educativas y el mantenerse en el campo de aplicación para el que se estudió. Aun cuando los predictores disponibles expresan de manera limitada el problema, revelan la necesidad de valorar e indagar con mayor profundidad sus causas y plantear soluciones viables, pues los costos del desperdicio de profesionales son significativos: los inmigrantes con estudios universitarios empleados en trabajos poco calificados pierden más de 39 mil millones de dólares en salarios y el fisco más de 10 mil millones en recibos de impuestos no realizados (Batalova, Fix y Bachmeier, 2016).

\section{CUADRO 3}

Inmigrantes mexicanos con estudios superiores en áreas de conocimiento en salud de 22 a 70 años de edad, 2012-2016

\begin{tabular}{|c|c|c|c|c|c|c|c|}
\hline \multicolumn{2}{|r|}{ Variable dependiente } & \multicolumn{2}{|c|}{ Modelo 1} & \multicolumn{2}{|c|}{ Modelo 2} & \multicolumn{2}{|c|}{ Modelo 3} \\
\hline 0 & & \multirow{2}{*}{\multicolumn{2}{|c|}{$\begin{array}{c}\text { Ocupado } \\
\text { Desocupado } \\
\text { o inactivo }\end{array}$}} & \multirow{2}{*}{\multicolumn{2}{|c|}{$\begin{array}{c}\text { Ocupación } \\
\text { profesional } \\
\text { Ocupación } \\
\text { no profesional }\end{array}$}} & \multirow{2}{*}{\multicolumn{2}{|c|}{$\begin{array}{c}\text { Ocupación } \\
\text { en salud } \\
\text { Ocupación distinta } \\
\text { a la salud }\end{array}$}} \\
\hline 1 & & & & & & & \\
\hline & $\begin{array}{c}\text { Variables } \\
\text { independientes }\end{array}$ & $\begin{array}{l}\text { Odds } \\
\text { Ratio }\end{array}$ & $P>z$ & $\begin{array}{l}\text { Odds } \\
\text { Ratio }\end{array}$ & $P>z$ & $\begin{array}{l}\text { Odds } \\
\text { Ratio }\end{array}$ & $P>z$ \\
\hline $\mathrm{cr}$ & $\begin{array}{r}\text { Ocupación } \\
\text { profesional en salud }\end{array}$ & & & & & & \\
\hline & $\begin{array}{r}\text { Otra ocupación } \\
\text { profesional }\end{array}$ & 0.77805 & -0.251 & & & & \\
\hline & No profesional & 8.25136 & $2.110^{* * *}$ & & & & \\
\hline $\mathrm{Cr}$ & $\begin{array}{r}\text { Desempleado } \\
\text { o inactivo }\end{array}$ & & & & & & \\
\hline & Ocupado & & & & & 4.54804 & $1.515^{* *}$ \\
\hline $\mathrm{cr}$ & Hombre & & & & & & \\
\hline & Mujer & 0.26634 & $-1.323^{* * *}$ & 1.08464 & 0.081 & 0.83964 & -0.175 \\
\hline $\mathrm{Cr}$ & De 22 a 44 años & & & & & & \\
\hline & De 45 a 70 años & 0.90033 & -0.105 & 1.25376 & 0.226 & 1.05021 & 0.049 \\
\hline $\mathrm{cr}$ & Licenciatura & & & & & & \\
\hline & Posgrado & 1.42806 & 0.356 & 2.59002 & $0.952^{* * *}$ & 2.05336 & $0.719^{* * *}$ \\
\hline
\end{tabular}




\begin{tabular}{|c|c|c|c|c|c|c|c|}
\hline \multicolumn{2}{|r|}{ Variable dependiente } & \multicolumn{2}{|c|}{ Modelo 1} & \multicolumn{2}{|c|}{ Modelo 2} & \multicolumn{2}{|c|}{ Modelo 3} \\
\hline 0 & & \multicolumn{2}{|c|}{ Ocupado } & \multicolumn{2}{|c|}{$\begin{array}{l}\text { Ocupación } \\
\text { profesional }\end{array}$} & \multicolumn{2}{|c|}{$\begin{array}{l}\text { Ocupación } \\
\text { en salud }\end{array}$} \\
\hline \multirow[t]{2}{*}{1} & & \multicolumn{2}{|c|}{$\begin{array}{l}\text { Desocupado } \\
\text { o inactivo }\end{array}$} & \multicolumn{2}{|c|}{$\begin{array}{l}\text { Ocupación } \\
\text { no profesional }\end{array}$} & \multicolumn{2}{|c|}{$\begin{array}{c}\text { Ocupación distinta } \\
\text { a la salud }\end{array}$} \\
\hline & $\begin{array}{c}\text { Variables } \\
\text { independientes }\end{array}$ & $\begin{array}{l}\text { Odds } \\
\text { Ratio }\end{array}$ & $P>z$ & $\begin{array}{l}\text { Odds } \\
\text { Ratio }\end{array}$ & $P>z$ & $\begin{array}{l}\text { Odds } \\
\text { Ratio }\end{array}$ & $P>z$ \\
\hline \multirow[t]{2}{*}{$\mathrm{cr}$} & $\begin{array}{r}\text { Medicina } \\
\text { y enfermería }\end{array}$ & & & & & & \\
\hline & Otra área de la salud & 1.35607 & 0.305 & 0.57170 & $-0.559^{* *}$ & 0.41544 & $-0.878^{* *}$ \\
\hline \multirow[t]{2}{*}{$\mathrm{cr}$} & Habla inglés & & & & & & \\
\hline & No habla inglés & 0.38660 & $-0.950^{* * *}$ & 0.85473 & -0.157 & 0.48107 & $-0.732^{* *}$ \\
\hline \multirow[t]{3}{*}{$\mathrm{cr}$} & En Estados Unidos ${ }^{1}$ & & & & & & \\
\hline & En ambos países & 1.09674 & 0.092 & 1.75851 & $0.564^{*}$ & 1.61982 & $0.482^{*}$ \\
\hline & En México & 1.31857 & 0.277 & 2.78466 & $1.024^{* *}$ & 2.21633 & $0.796^{* * *}$ \\
\hline \multirow[t]{2}{*}{$\mathrm{cr}$} & Ciudadano & & & & & & \\
\hline & No ciudadano & 0.65869 & $-0.417^{*}$ & 0.37266 & $-0.987^{* * *}$ & 0.32716 & $-1.117^{* * *}$ \\
\hline \multirow[t]{3}{*}{$\mathrm{cr}$} & Reciente arribo $^{2}$ & & & & & & \\
\hline & Largo arribo & 1.52087 & 0.419 & 0.43268 & $-0.838^{* *}$ & 0.42526 & $-0.855^{* *}$ \\
\hline & _cons & 0.30698 & $-1.181^{* *}$ & 0.26953 & $-1.311^{* * *}$ & 2.60864 & $0.959^{*}$ \\
\hline
\end{tabular}

${ }^{1}$ Tipo de formación o país de formación académica, una medida aproximada del lugar donde se realizaron los estudios de educación superior con base en Gaspar, 2016.

${ }^{2}$ Reciente arribo: ingresaron a Estados Unidos entre 2006-2016; largo arribo: ingresaron antes de 2006.

${ }^{*} \mathrm{p}<0.05,{ }^{* *} \mathrm{p}<0.01,{ }^{* * *} \mathrm{p}<0.001$. Se utilizó un ponderador relativo.

Fuente: estimación propia con base en la ACS, 2012-2016.

\section{Conclusiones}

Para México la migración interna e internacional de los profesionales de la salud comprende impactos relevantes en la conformación de la oferta del servicio a escalas nacional y local, así como en otros ámbitos relacionados con la investigación y la innovación en el sector. La planeación y gestión de recursos humanos calificados de la salud es indispensable bajo marcos institucionales que garanticen el derecho a la libre movilidad de las personas, a la elección del lugar de residencia, así como a trasladarse a otras naciones si así conviene a su desarrollo profesional o a la realización de sus planes de vida. Poner restricciones a la emigración o cerrar las puertas a la inmigración de graduados en áreas de medicina y ciencias de la salud no servirá para mejorar las condiciones de salud 
de la población de los países afectados por la migración y la escasez de profesionales de la salud, sino hasta en tanto se aborden las causas que hacen que emigren y que no retornen, al igual que las razones que subyacen al déficit de esos profesionales. Se trata, en el fondo, como se ha argumentado, de un problema de naturaleza estructural asociado a las dinámicas de desarrollo desigual que caracterizan al capitalismo contemporáneo.

Si bien la inmigración de mexicanos profesionales de la salud, como grupo de inmigrantes en Estados Unidos, no es el más numeroso, sí se encuentra entre los principales núcleos de migrantes calificados. Las implicaciones sobre la disponibilidad de esos profesionales para la atención de las necesidades de salud en México justifican, por sí mismas, su trascendencia como objeto de estudio y tema de atención para el gobierno mexicano y sus instituciones; asimismo, para el diseño e implementación de políticas de retención de potenciales migrantes, que garanticen salarios más altos y condiciones laborales estables.

Las asimetrías económicas y de desarrollo que caracterizan a México y Estados Unidos y que se profundizan en el contexto de la globalización neoliberal constituyen el cimiento de los enfoques estructurales que ayudan a comprender la migración de los profesionales de la salud, aunado a la demanda de una nación en avanzado proceso de envejecimiento que requiere atender las crecientes necesidades de cuidados y de atención en materia de salud.

Un número importante de inmigrantes mexicanos en Estados Unidos y de nacionales en México con estudios en áreas de la salud están siendo subvalorados o se encuentran inactivos y son obligados a cambiar de campo ocupacional. Ante un déficit de profesionales de la salud en ambos países, los resultados ponen de relieve que más que un simple desequilibrio de mercado se trata de una consecuencia de las profundas asimetrías entre países generadas en el marco de la globalización neoliberal. Ello deviene, por un lado, en un desperdicio de recursos humanos y transferencia de recursos monetarios devengados en su formación. Más aún, el problema adquiere una dimensión más crítica si se considera que México atraviesa un proceso de envejecimiento, con un creciente déficit de profesionales de la salud en el nivel estatal y con flujos migratorios persistentes y en ascenso. La inactividad, el desempleo, la subutilización, el subempleo, el empleo en condiciones críticas, los bajos ingresos por trabajo y la desvalorización de los profesionales de la salud configuran una dimensión crítica de la migración mexicana calificada que no puede ni debe ser soslayada. 


\section{Referencias}

Ávila Martínez, José Luis y Selene Gaspar Olvera (2019), «Migración de profesionales de enfermería y del cuidado de la salud de México a Estados Unidos, 2010-2015», IV Congreso Internacional Salud y Migración, organizado por la Universidad Popular Autónoma del Estado de Puebla y RIID, en la ciudad de Puebla, México, del 11 al 13 de enero de 2018. En prensa.

Aragonés, Ana María y Uberto Salgado (marzo y abril, 2014), «خ̀Competencia internacional por la migración altamente calificada?» Comercio Exterior, 64(2), en http:// revistas.bancomext.gob.mx/rce/magazines/756/5/competencia-internacional. pdf

Aparicio Cabrera, Abraham (2006), «Efectos psicosociales del desempleo», Revista de Investigación Social (RIS), pp. 67-82, en http://wWw.economia.unam.mx/profesores/a aparicio/Efectos.pdf

Azqueta Oyarzun, Diego, Guillermina Gavaldón Hernández y Leonor Margalef García (septiembre-diciembre, 2007), "Educación y desarrollo: ¿̇capital humano o capital social?», Revista de Educación, 344, pp. 265-283, en https://www.researchgate.net/ publication/28194610_Educacion_y_desarrollo_capital_humano_o_capital_social

Basch, Stephen (2003), «International migration of health working: labour and social issues», en http://citeseerx.ist.psu.edu/viewdoc/download?doi=10.1.1.295.8665\&r ep $=$ rep 18 type $=$ pdf

Batalova, Jeanne, Michael Fix y James D. Bachmeier (2016), "Untapped talent: the costs of brain waste among highly skilled immigrants in the United States», en https:// WWW.migrationpolicy.org/research/untapped-talent-costs-brain-waste-among -highly-skilled-immigrants-united-states

Batalova, Jeanne, Michael Fix y Peter A. Creticos (2008), Uneven progress: the employment pathways of skilled immigrants in the United States, Washington DC, Migration Policy Institute, en https://www.immigrationresearch.org/report/migration-policyinstitute/uneven-progress-employment-pathways-skilled-immigrants-united-stat

Bayley, Ajay y Clara Mulder (2017), "Highly skilled migration between the global North and South: gender, life courses and institutions", Journal of Ethnic and Migration Studies, 43(16), pp. 2689-2703, en https://www.tandfonline.com/doi/full/10.10 80/1369183X.2017.1314594

Bourdieu, Pierre (1979), "Los tres estados del capital cultural», Sociológica (5), pp. 11-17, en http://sociologiac.net/biblio/Bourdieu-LosTresEstadosdelCapitalCultural.pdf 
Burgos Flores, Benjamín y Karla López Montes (2010), «La situación del mercado laboral de profesionistas», Revista de Educación Superior, 39(156).

Canales Cerón, Alejandro I. (2008), «Remesas y desarrollo en América Latina: una relación en busca de teoría», Migración y desarrollo, 6(11), pp. 5-30, en http://www. scielo.org.mx/pdf/myd/n11/n11a1.pdf

Chacón Avila, Luis (2002), «Reflexiones sobre la migración de recursos humanos calificados», Amérique Latine Histoire et Mémoire. Les Cahiers ALHIM, en http://journals. openedition.org/alhim/700

Delgado Wise, Raúl y Selene Gaspar Olvera (2018), «Las remesas a contraluz del discurso dominante: evidencias a partir de la experiencia mexicana», en Dirk Bornschein (comp.), Hacia un salto cualitativo. Migración y desarrollo en México y el norte de Centroamérica, Guatemala, Flacso, pp. 225-245.

Delgado Wise, Raúl y David Martin (octubre-diciembre, 2015), "La economía política del arbitraje laboral global», Problemas del Desarrollo, 183(46), en http://www. revistas.unam.mx/index.php/pde/article/view/52622/46825

Díaz Forero, Jorge Eliecer (2018), Avances del marco teórico conceptual: migración de talentos estratégicos (MTE). Expectativas entre el retorno y el arraigo (ERA), Venezuela 1999-2019, en https://www.researchgate.net/publication/325203551_Avances_del_Marco_ Teorico_Conceptual_Migracion_del_Talento_Estrategico_MTE_Expectativas entre_el_Retorno_y_el_Arraigo_ERA_Venezuela_1999-2019

Gaspar Olvera, Selene (3 de octubre de 2017), «Integración de los inmigrantes calificados en Estados Unidos (2011-2015)», Odisea. Revista de Estudios Migratorios (4), pp. 85-124, en https://publicaciones.sociales.uba.ar/index.php/odisea/article/ view/2492

Gaspar Olvera, Selene (2016), iEstudiar para emigrar o emigrar para estudiar? Procesos de integración de los inmigrantes mexicanos calificados en Estados Unidos (tesis de maestría), México, Universidad Nacional Autónoma de México, en http://132.248.9.195/ ptd2016/mayo/086335676/Index.html

Giorguli, Saucedo Silvia y Selene Gaspar Olvera (2008), Inserción ocupacional, ingreso y prestaciones de los mexicanos en Estados Unidos, México, Consejo Nacional de Población, en http://omi.conapo.gob.mx/work/models/OMI/Resource/473/Selene2007. pdf

Instituto Nacional de Estadística, Georgrafía e Informática (2014), "Estadísticas a propósito del día del médico» en https://www.inegi.org.mx/contenidos/salade prensa/aproposito/2014/medico0.pdf 
Moullan, Yasser y Yann Bourgueil (noviembre de 2014), "The international migration of doctors: impact and political implications», Questions D'économie de la Santé (203), en https://www.irdes.fr/english/issues-in-health-economics/203-theinternational-migration-of-doctors-impacts-and-political-implications.pdf

Lowell Lindsay, Allan Findlay y Emma Stewart (2004), «Brain strain optimising highly skilled migration from developing countries», Asylum and Migration Working Paper 3, Institute for Public Policy Research (IPPR), en https://www.ippr.org/files/ images/media/files/publication/2011/05/brainstrain_1365.pdf

Márquez Covarrubias, Humberto (2012), Diccionario critico de migración y desarrollo, México, Miguel Ángel Porrúa/Universidad Autónoma de Zacatecas/Organización de las Naciones Unidas para la Educación, la Ciencia y la Cultura/Red Internacional de Migración y Desarrollo.

Organización Panamericana de la Salud (OPS) (2013), «Migración calificada en salud. Impacto financiero, reconocimiento de títulos. Retos y perspectivas en los países de la región andina», Iris. Repositorio institucional para intercambio de información, OPS, en http://www.observatoriorh.org/sites/default/files/webfiles/fulltext/2013/ migracali_subreg_andina_2013.pdf

Organización para la Cooperación y el Desarrollo Económicos (2016), «Se necesitan profesionales de la salud con habilidades correctas en los lugares apropiados, afirma la OCDE», en https://www.oecd.org/centrodemexico/medios/se-necesitanprofesionales-de-la-salud-con-habilidades-correctas-en-lugares-apropiados-ocde. htm

OCDE (2015), «Panorama de la salud, 2015. Indicadores de la OCDE», en https://www. oecd-ilibrary.org/docserver/9789264270626-es.pdf? expires $=1571186821 \& \mathrm{id}=\mathrm{id} \& \mathrm{ac}$ cname $=$ guest \&checksum $=28 \mathrm{~B} 49 \mathrm{~B} 76 \mathrm{D} 69 \mathrm{C} 02 \mathrm{FB} 475 \mathrm{FED} 7 \mathrm{BDA}$ 6BE66D

Organización Mundial de la Salud (2013), «Global health workforce shortage to reach 12.9 million in coming decades», en http://www.who.int/mediacentre/news/ releases/2013/health-workforce-shortage/en/

Presidents' Alliance (2019), «Expanding eligibility for professional and occupational licensing for immigrants», en https://www.presidentsimmigrationalliance.org/ wp-content/uploads/2019/09/2019-09-Expanding-Eligibility-for-Professionaland-Occupational-Licensing-for-Immigrants.pdf

Tigau, Camelia (2015), "La imagen de la migración calificada en América del Norte», Migraciones Internacionales, 8(2), pp. 195-229, en https://migracionesinternacionales. colef.mx/index.php/migracionesinternacionales/article/view/605 
Thornton, Roberto J. y Edward J. Timmons (2015), The de-licensing of occupations in the United States, United States, Bureau of Labour Statistics, en https://www.bls.gov/ opub/mlr/2015/article/the-de-licensing-of-occupations-in-the-united-states.htm

Thurow, Lester C. (1975), Generating inequality: mechanisms of distribution in the U.S. economy, New York, Basic Books, en http://mlncn.com/lib/rev/generatinginequality/ index.html

Yetter, A. Erin (2013), «Why scarce resources are sometimes unemployed», Economic Research, en https:/files.stlouisfed.org/files/htdocs/pageone-economics/uploads/ newsletter/2013/PageOne1013_Why_Scarce_Resources_Are_Sometimes_Unemployed .pdf

Yildiz, Nejdan (2010), «Reducing brain waste: skilled immigrants and the recognition of foreign credentials in the United States», en http://www.globaltalentbridge. org/evaluation/ForeignCredentialRecognitionUS.pdf

Young, Aaron, Humayun J. Chaudhry, Xiaomei Pei, Katie Arnhart, Michael Dugan y Scott A. (2019), «FSMB Census of Licensed Physicians in the United States, 2018», Journal of Medical Regulation, 105(217), en https://www.fsmb.org/siteassets/ advocacy/publications/2018census.pdf

\section{2}

